\title{
Normal brain imaging accompanies neuroimmunologically justified, autoimmune encephalomyelitis
}

Daiki Takewaki, MD, Youwei Lin, MD, Wakiro Sato, MD, PhD, Hirohiko Ono, MD, Masakazu Nakamura, MD, PhD, Manabu Araki, MD, PhD, Tomoko Okamoto, MD, PhD, Yuji Takahashi, MD, PhD, Yukio Kimura, MD, PhD,

Miho Ota, MD, PhD, Noriko Sato, MD, PhD, and Takashi Yamamura, MD, PhD

Neurol Neuroimmunol Neuroinflamm 2018;5:e456. doi:10.1212/NXI.0000000000000456

\section{Abstract}

\section{Objective}

To examine cases with a clinical course, signs, and symptoms mimicking MS, but without abnormalities on conventional MRI.

\section{Methods}

Among 550 people with a tentative diagnosis of MS or neuromyelitis optica spectrum disorder (NMOSD), we selected patients, who met the $2010 \mathrm{McD}$ onald diagnosis criteria for MS, but did not show abnormal findings on conventional brain and spinal cord MRI. After evaluating their clinical data, we analyzed fractional anisotropy (FA) values in the brain white matter on diffusion tensor MRIs and the frequencies of B-cell subsets in the peripheral blood in the corresponding cases as compared to healthy controls.

\section{Results}

Eleven patients (age: $41.1 \pm 8.0$ years, 9 women and 2 men) met the selection criteria. They were functionally disabled, with a median expanded disability status scale score of 6.0 (2.0-8.0). CSF oligoclonal bands were negative in all cases. IV methylprednisolone and plasmapheresis (PP) were found to be efficacious. Diffusion tensor MRI analysis revealed extensive white matter abnormalities characterized by significantly decreased FA values. The frequency of plasmablasts in the peripheral blood was significantly increased in these patients similar to NMOSD.

\section{Conclusions}

The neurologic disabilities in these patients could be ascribed to brain white matter damage, as revealed by MRI analysis, whereas the efficacy of PP and B-cell abnormalities in the patients suggested an autoimmune-mediated pathogenesis. In the differential diagnosis of MS, we propose that this condition be referred to as, "Normal-appearing Imaging-associated, Neuroimmunologically Justified, Autoimmune encephalomyelitis."
Correspondence

Dr. Yamamura

yamamura@ncnp.go.jp 


\section{Glossary}

AQP4 = aquaporin-4; DTI = diffusion tensor image; EDSS = Expanded Disability Status Scale; FA = fractional anisotropy; FLAIR = fluid-attenuated inversion recovery; FOV = field of view; HC = healthy control; HTLV = human T-cell leukemia virus; IFN- $\beta=$ interferon- $\beta$; IVMP $=$ IV methylprednisolone; MOG $=$ myelin oligodendrocyte glycoprotein $;$ NCNP $=$ National Center of Neurology and Psychiatry; NINJA = Normal-appearing Imaging-associated, Neuroimmunologically Justified, Autoimmune encephalomyelitis; NMOSD = neuromyelitis optica spectrum disorder; $\mathbf{O B}=$ oligoclonal band; PBMC = peripheral blood mononuclear cell; PP = plasmapheresis; SSEP = somatosensory evoked potential; TBSS = tract-based spatial statistics; VEP = visual evoked potential.

To diagnose and evaluate the severity of MS, MRIs are immensely valuable. However, in a small proportion of patients who are clinically diagnosed as having MS, the clinical manifestations and MRI findings could be dissociated. ${ }^{1}$ The widely used $2010 \mathrm{McD}$ onald criteria allow diagnosis of MS in cases without abnormalities on conventional brain and spinal cord MRIs, provided that objective clinical evidence for dissemination of lesions in terms of both space and time can be confirmed. ${ }^{2}$ Nevertheless, such patients have generally been excluded from MS cohort studies, ${ }^{3}$ under the assumption that negative MRI findings could never coexist with demyelination, and do not formally exclude the possibility of psychiatric or somatoform disorders.

The purpose of our research was to gain insights into the pathogenesis of the disease in patients who met the 2010 McDonald criteria, but who had normal-appearing brain and spinal cord MRIs, and to distinguish this population from those with MS. We show that normal-appearing MRI in these patients could be associated with autoimmune encephalomyelitis, accompanied by B-cell abnormalities. We propose that this condition be called as "Normal-appearing Imagingassociated, Neuroimmunologically Justified, Autoimmune encephalomyelitis" (NINJA).

\section{Methods}

\section{Selection of patients and controls}

We surveyed the medical records of 550 individuals who attended the Multiple Sclerosis Center of the National Center of Neurology and Psychiatry in 2016 and subsequently identified 11 patients who met the $2010 \mathrm{McDonald}$ criteria, despite having normal-appearing conventional MRIs of both the brain and spinal cord. Repeated medical examinations by independent neurologists had confirmed objective clinical evidence, such as a pyramidal pattern of weakness associated with more than 2 lesions, or objective clinical evidence of 1 lesion along with reasonable historical evidence of a previous attack. ${ }^{2}$ Clinical history, physical examination, and results of laboratory tests had excluded neuromyelitis optica spectrum disorders (NMOSDs), tumor, syphilis, cerebrovascular disease, spondylotic myelopathy, acute disseminated encephalomyelitis, syringomyelia, spinocerebellar degeneration, human T-cell leukemia virus-1 (HTLV-1)-associated myelopathy, collagen disease, Sjögren syndrome, Behcet disease, sarcoidosis, mitochondrial encephalomyopathy, and progressive multifocal leukoencephalopathy.

To exclude the possibility of NMOSD, serum anti-aquaporin4 (AQP4) antibodies and anti-myelin oligodendrocyte glycoprotein (MOG) antibodies were measured by cell-based assays. ${ }^{4}$ For flow cytometric measurement of B-cell subpopulations, we collected blood samples from the 11 patients under study and from 17 healthy controls (HCs). To evaluate fractional anisotropy (FA) values in the brain white matter, brain MRIs were obtained from 9 of the patients and from 24 HCs. All the patients were in the nonrecurrent period at the time of MR and flow cytometry examinations.

\section{Standard protocol approvals, registrations, and patient consents}

The Ethics Committee of the NCNP on human experimentation approved the study, and written informed consent was obtained from all participants.

\section{Clinical analysis}

We analyzed the clinical demographics of the 11 patients, whom we later called NINJA, in terms of the following items: (1) onset age/disease duration/sex, (2) medical history and family history of autoimmune diseases/history of drug allergy, (3) objective clinical evidence of neurologic disability, (4) Expanded Disability Status Scale (EDSS), ${ }^{5}$ (5) laboratory examinations (blood test and CSF test), (6) electrophysiologic examinations (somatosensory evoked potential [SSEP] and visual evoked potential [VEP]), (7) brain and spinal cord MRIs, (8) efficacy of IV methylprednisolone (IVMP) and plasmapheresis (PP), and (9) efficacy of interferon- $\beta$ (IFN- $\beta$ ). The SSEP and VEP data were considered abnormal if the cutoff points (mean $\pm 2 \mathrm{SD}$ ) of the HC group, determined at the NCNP, were exceeded. The efficacy of IVMP and PP was evaluated based on the changes in both clinical signs and symptoms before and after treatment. We determined IFN- $\beta$ nonresponders based on the modified Rio score. ${ }^{6}$

\section{MRI analysis}

\section{MR data acquisition}

Imaging was performed on a 3-T MR system (Philips, Best, The Netherlands, or Siemens, Munich, Germany). Diffusion tensor images (DTIs) were acquired using the parameters previously described. ${ }^{7,8}$ We performed DTI in the axial plane 
(repetition time [TR]/echo time [TE], 5,760/62 or 8,300/73 ms; matrix, $80 \times 80$ or $76 \times 76$; field of view (FOV), $240 \times$ $240 \mathrm{~mm}$; 60 or 55 continuous transverse slices; slice thickness, $3 \mathrm{~mm}$ with no inter slice gap). To enhance the signal-to-noise ratio, acquisition was performed twice. Diffusion was measured along 15 or 12 noncollinear directions using a diffusionweighted factor in each direction for $1,000 \mathrm{~s} / \mathrm{mm}^{2}$, and 1 image was acquired without using any diffusion gradient. We also added a routine conventional MRI examination with the following protocols. MRI of the brain was performed using a 32-channel head coil. Imaging was performed using a sagittal 3D T1-weighted magnetization-prepared rapid gradient echo sequence $(\mathrm{TE} / \mathrm{TR}=7.18 / 3.46$ or $1,800 / 2.26 \mathrm{~ms}$, FOV $=261$ $\times 261$ or $250 \times 250 \mathrm{~mm}$, matrix size $=384 \times 384$ or $320 \times 288$, number of excitations (NEX) 1, slice thickness 0.6 or $0.8 \mathrm{~mm}$, 300 or 224 continuous transverse slices), sagittal 3D fluidattenuated inversion recovery (FLAIR) sequence (TE/ inversion time $[\mathrm{TI}] / \mathrm{TR}=4,700 / 1,600 / 290$ or $5,000 /$ $1,800 / 413 \mathrm{~ms}$, FOV $=260 \times 234$ or $250 \times 250 \mathrm{~mm}$, matrix size $=512 \times 460$ or $261 \times 261$, NEX 2 or 1 , slice thickness 0.55 or $1 \mathrm{~mm}, 340$ or 176 continuous transverse slices), and axial T2-weighted sequence $(\mathrm{TE} / \mathrm{TR}=4,491 / 80$ or $5,000 / 81 \mathrm{~ms}$, FOV $=230 \times 207$ or $220 \times 199$, matrix size $=640 \times 576$ or 512 $\times 348$, NEX 2, flip angle $=150$ or $140^{\circ}$, slice thickness $3 \mathrm{~mm}$ ). 3D T1-weighted images and 3D FLAIR images were also resliced to $3 \mathrm{~mm}$ in axial and coronal orientations. MRI of the spinal cord was performed using a spinal phased array coil. Cervical spinal imaging was performed using a sagittal T2weighted sequence $(\mathrm{TE} / \mathrm{TR}=3,000 / 90$ or $3,430 / 87 \mathrm{~ms}$, $\mathrm{FOV}=250 \times 250$ or $200 \times 200$, matrix size $=512 \times 512$ or 384 $\times 307$, NEX 1 or 2 , flip angle $=140$ or $150^{\circ}$, slice thickness $3 \mathrm{~mm})$, sagittal T1-weighted sequence $(\mathrm{TE} / \mathrm{TR}=582 / 8.5$ or $580 / 9.1 \mathrm{~ms}, \mathrm{FOV}=250 \times 250$ or $200 \times 200$, matrix size $=512$ $\times 512$ or $256 \times 256$, NEX 1 or 2 , flip angle $=110$ or $150^{\circ}$, slice thickness $3 \mathrm{~mm})$, and axial T2-weighted sequence $(\mathrm{TE} / \mathrm{TR}=$ $2,848 / 90$ or $3,130 / 91 \mathrm{~ms}, \mathrm{FOV}=140 \times 115$ or $140 \times 140$, matrix size $=352 \times 289$ or $256 \times 230$, NEX 1 , flip angle $=140$ or $150^{\circ}$, slice thickness $5 \mathrm{~mm}$ ). Thoracic spinal imaging was performed using a sagittal T2-weighted sequence $(\mathrm{TE} / \mathrm{TR}=$ $3,000 / 90$ or $3,230 / 81 \mathrm{~ms}, \mathrm{FOV}=350 \times 350$ or $320 \times 320$, matrix size $=576 \times 576$ or $448 \times 358$, NEX 1 or 2 , flip angle $=$ 120 or $150^{\circ}$, slice thickness $3 \mathrm{~mm}$ ), sagittal T1-weighted sequence $(\mathrm{TE} / \mathrm{TR}=623 / 7.5$ or $562 / 8.9 \mathrm{~ms}, \mathrm{FOV}=350 \times 350$ or $320 \times 320$, matrix size $=640 \times 640$ or $384 \times 288$, NEX 1 or 2, flip angle $=150$ or $140^{\circ}$, slice thickness $3 \mathrm{~mm}$ ), and axial T2weighted sequence $(\mathrm{TE} / \mathrm{TR}=3,279 / 90$ or $3,130 / 91 \mathrm{~ms}$, FOV $=160 \times 160$ or $140 \times 140$, matrix size $=400 \times 400$ or 256 $\times 256$, NEX 1, flip angle $=145$ or $150^{\circ}$, slice thickness $5 \mathrm{~mm}$ ).

\section{MR data analysis}

We evaluated the FA values using a processing technique known as tract-based spatial statistics (TBSS) analysis. ${ }^{9}$ TBSS is available as part of the FSL 5.0 software package. ${ }^{10}$ TBSS projects each subject's aligned FA image to the FMRIB58_FA template, which is supplied with FSL software, onto a binary mask, called the skeleton image, derived from a mean FA image, limiting the FA value to $>0.2$. This yields skeletonized FA data.

\section{Statistical analysis of MR data}

We evaluated the differences in demographic and clinical data between the 2 groups. The statistical analyses were performed using Prism software version 5.0 (GraphPad Software, San Diego, CA). Skeletonized FA data were analyzed to assess the difference in FA values between NINJA and HCs, controlling for age, sex, and MRI system. The level of statistical significance was set at $p<0.05$, with family-wise error rate correction for multiple comparisons using the FSL "Threshold-Free Cluster Enhancement" option in "randomize" with 10,000 permutations. ${ }^{11,12}$

\section{Flow cytometric analysis}

\section{Reagents}

The following fluorescence or biotin-labeled monoclonal antibodies were used for flow cytometry: anti-CD19-APCCy7, anti-CD27-PE-Cy7, and anti-CD180-PE (BD Biosciences, San Jose, CA); anti-CD38-FITC (Beckman Coulter, Brea, CA); and anti-CD3-PerCP-Cy5.5 and anti-CD14-APC (BioLegend, San Diego, CA).

\section{Cell preparation and flow cytometry}

Peripheral blood mononuclear cells (PBMCs) were isolated by density gradient centrifugation using Ficoll-Paque Plus (GE Healthcare Bioscience, Oakville, ON, Canada). B-cell populations were defined in reference to our previous articles ${ }^{13,14}$ : total $\mathrm{B}$ cells, $\mathrm{CD}^{-} \mathrm{CD} 14^{-} \mathrm{CD} 19^{+}$; naive $\mathrm{B}$ cells, $\mathrm{CD} 3^{-} \mathrm{CD} 14^{-} \mathrm{CD} 19^{+} \mathrm{CD} 27^{-}$; memory B cells, $\mathrm{CD} 3^{-} \mathrm{CD} 14^{-} \mathrm{CD} 19^{+} \mathrm{CD} 27^{+} \mathrm{CD} 180^{+}$; and plasmablasts, $\mathrm{CD} 3^{-} \mathrm{CD} 14^{-} \mathrm{CD} 19^{+} \mathrm{CD} 27^{\text {high }} \mathrm{CD} 38^{\text {high }} \mathrm{CD} 180^{-}$. To evaluate the frequency of each $\mathrm{B}$-cell population, $\mathrm{PBMCs}$ were stained with anti-CD19-APC-Cy7, anti-CD27-PE-Cy7, antiCD38-FITC, anti-CD180-PE, anti-CD3-PerCP-Cy5.5, and antiCD14-APC. After completing incubation, cells were washed and resuspended in phosphate-buffered saline supplemented with $0.5 \%$ bovine serum albumin and analyzed by FACS Canto II (BD Biosciences, Franklin Lakes, NJ) according to the manufacturer's instructions.

\section{Statistical analysis of flow cytometry data}

We used Diva software (BD Biosciences, Franklin Lakes, NJ) to analyze the flow cytometric data. We used Prism software (GraphPad Software, La Jolla, CA) for statistical analysis of the data, using the Mann-Whitney $U$ test and Fisher exact test. The significance level was set at a $p$ value $<0.05$.

\section{Data availability}

Anonymized data will be shared on request from any qualified investigator.

\section{Results}

\section{Clinical analysis of the NINJA cohort}

Eleven patients (9 women and 2 men) fulfilled the selection criteria with the following clinical features (detailed data are shown in table 1, tables e-1 and e-2, links.lww.com/NXI/A44); values are expressed as number, mean $\pm \mathrm{SD}$, or median (range). Their mean age at onset and disease duration were $26.9 \pm 7.3$ years and $14.2 \pm$ 
Table 1 Demographic and clinical data of 11 patients with NINJA

\begin{tabular}{|c|c|c|c|c|c|c|c|}
\hline Case & $\begin{array}{l}\text { Age, } \\
\text { y/sex }\end{array}$ & $\begin{array}{l}\text { Disease } \\
\text { duration, y }\end{array}$ & EDSS & $\begin{array}{l}\text { Pyramidal } \\
\text { weakness }\end{array}$ & $\begin{array}{l}\text { Visual } \\
\text { impairment }\end{array}$ & Other neurologic findings & $\begin{array}{l}\text { Improvement items after } \\
\text { IVMP or PP }\end{array}$ \\
\hline 1 & $35 / F$ & 16 & 5.5 & Yes & Yes* & $\begin{array}{l}\text { Cognitive impairment/convulsion/ } \\
\text { dysesthesia, hypoalgesia, and } \\
\text { pallhypesthesia in } 4 \text { limbs }\end{array}$ & $\begin{array}{l}\text { Bilateral visual disturbance/limb } \\
\text { weakness in } 4 \text { limbs }\end{array}$ \\
\hline 2 & $47 / F$ & 13 & 7.5 & Yes & Yes & $\begin{array}{l}\text { Cognitive impairment/dysesthesia } \\
\text { and hypoalgesia in } 4 \text { limbs and the } \\
\text { trunk }\end{array}$ & Limb weakness in both upper limbs \\
\hline 3 & $20 / F$ & 2 & 8 & Yes & No & $\begin{array}{l}\text { Convulsion/dysesthesia in both lower } \\
\text { limbs and trunk/bladder and bowel } \\
\text { dysfunction }\end{array}$ & $\begin{array}{l}\text { Limb weakness in both upper limbs/ } \\
\text { sensory disturbance in } 4 \text { limbs and } \\
\text { the trunk }\end{array}$ \\
\hline 4 & $40 / F$ & 13 & 2 & Yes & No & Hypoalgesia in 4 limbs & $\begin{array}{l}\text { Right dominant limb weakness in } 4 \\
\text { limbs/sensory disturbance in } 4 \text { limbs }\end{array}$ \\
\hline 5 & $41 / \mathrm{M}$ & 3 & 5 & Yes & Yes & $\begin{array}{l}\text { Dysesthesia and hypoalgesia on the } \\
\text { left side of the body }\end{array}$ & $\begin{array}{l}\text { Limb weakness in left upper limb/ } \\
\text { sensory disturbance on the left side } \\
\text { of the body/gait speed }\end{array}$ \\
\hline 6 & $41 / \mathrm{F}$ & 7 & 7 & Yes & Yes & Hypoalgesia in the left lower limb & $\begin{array}{l}\text { Sensory disturbance in the left lower } \\
\text { limb }\end{array}$ \\
\hline 7 & $53 / F$ & 17 & 5.5 & Yes & Yes & $\begin{array}{l}\text { Hypoalgesia on the left side of the } \\
\text { body/bladder and bowel dysfunction }\end{array}$ & $\begin{array}{l}\text { Bilateral visual disturbance/sensory } \\
\text { disturbance in both lower limbs/gait } \\
\text { speed/bladder and bowel } \\
\text { dysfunction }\end{array}$ \\
\hline 8 & $43 / F$ & 22 & 6 & Yes & Yes & $\begin{array}{l}\text { Dysesthesia and hypoalgesia on the } \\
\text { left side of the body }\end{array}$ & $\begin{array}{l}\text { Limb weakness on the left side of the } \\
\text { body/sensory disturbance in left } \\
\text { upper limb/gait speed }\end{array}$ \\
\hline 9 & $44 / \mathrm{M}$ & 21 & 6 & Yes & Yes & $\begin{array}{l}\text { Dysesthesia, hypoalgesia, and } \\
\text { pallhypesthesia in } 4 \text { limbs }\end{array}$ & $\begin{array}{l}\text { Limb weakness in both lower limbs/ } \\
\text { sensory disturbance in } 4 \text { limbs }\end{array}$ \\
\hline 10 & $47 / F$ & 19 & 6.5 & Yes & Yes* & $\begin{array}{l}\text { Prosopagnosia/dysesthesia, } \\
\text { hypoalgesia, and pallhypesthesia in } 4 \\
\text { limbs and trunk/bladder and bowel } \\
\text { dysfunction }\end{array}$ & $\begin{array}{l}\text { Bilateral visual disturbance/limb } \\
\text { weakness in both lower limbs/ } \\
\text { bladder and bowel dysfunction }\end{array}$ \\
\hline 11 & $41 / \mathrm{F}$ & 23 & 8 & Yes & Yes* & $\begin{array}{l}\text { Cognitive impairment/ } \\
\text { prosopagnosia/hypoalgesia and } \\
\text { pallhypesthesia in } 4 \text { limbs/bladder } \\
\text { and bowel dysfunction }\end{array}$ & $\begin{array}{l}\text { Bilateral visual disturbance/left } \\
\text { dominant limb weakness in } 4 \text { limbs }\end{array}$ \\
\hline
\end{tabular}

Abbreviations: EDSS = Expanded Disability Status Scale; IVMP = IV methylprednisolone; NINJA = Normal-appearing Imaging-associated, Neuroimmunologically Justified, Autoimmune encephalomyelitis; PP = plasmapheresis; Yes* = visual impairment with an afferent pupillary defect.

7.1 years, respectively. Two of the patients had a medical history of idiopathic thrombocytopenic purpura or ulcerative colitis, and other 2 had a family history of rheumatoid arthritis or chronic inflammatory demyelinating polyneuropathy. Nine of the patients had a history of drug allergy. In terms of objective evidence for neurologic dysfunctions, all patients showed pyramidal weakness, whereas 3 showed visual impairment with an afferent pupillary defect. The median of the current EDSS score was 6.0 (2.0-8.0), with EDSS score of $>6.0$ in 7 patients. From the description of medical records, we were able to evaluate the changes in the EDSS within the past 5 years in 7 of the 11 patients. The EDSS increased in 4 , unchanged in 2 , and decreased in 1 patient over time (figure $\mathrm{e}-1$, links.lww.com/NXI/A43).

In blood tests, antithyroid peroxidase antibody was detected in a single patient, but no significant antibody titers were detected in any of the patients for anti-AQP4 antibodies, anti-MOG antibodies, antinuclear antibodies, anti-SS-A and SS-B antibodies, antineutrophil cytoplasmic antibodies, anticardiolipin antibodies, antithyroglobulin antibodies, and anti-HTLV-1 antibodies. Lupus anticoagulant, angiotensin-converting enzyme, and soluble interleukin-2 receptor were not detected, and Treponema pallidum hemagglutination tests were negative in all patients. All available data from CSF analysis indicated that cell counts were within the normal limits (10/ 10 patients), the immunoglobulin $\mathrm{G}$ index was not increased (7/7 patients), and oligoclonal bands (OBs) were absent (9/ 9 patients), which highlights a distinction from MS. Protein levels were increased in 2 of the 10 patients, and myelin basic protein levels were increased in 1 of the 10 patients. Electrophysiologic examinations were conducted in 8 patients; the SSEP test revealed extended central somatosensory conduction time in 2 patients and extended P100 latency in the VEP test in other 2 patients. The brain and spinal cord MRIs showed no intracranial space-occupying lesions or spinal canal stenosis in any of the patients. 
Table 2 Demographics of healthy controls and patients with NINJA in MRI analysis

\begin{tabular}{llll}
\hline & HCs & Patients with NINJA & $\boldsymbol{p}$ Value \\
\hline Number & 24 & 9 & \\
\hline Age (y) & $39.6 \pm 6.0$ & $39.2 \pm 8.2$ & 0.81 \\
\hline Female:male & $18: 6$ & $8: 1$ & 0.64 \\
\hline $\begin{array}{l}\text { MRI system Phillips: } \\
\text { Siemens }\end{array}$ & $14: 10$ & $5: 4$ & 1.00 \\
\hline
\end{tabular}

Abbreviations: $\mathrm{HC}=$ healthy control; NINJA = Normal-appearing Imaging-associated, Neuroimmunologically Justified, Autoimmune encephalomyelitis. Values are expressed as number or mean \pm SD.

IVMP given at the NCNP hospital was efficacious in all 11 patients, and improvement after PP was also confirmed at NCNP in 9 of the 10 patients. Three patients had previously been treated with IFN- $\beta$, but the treatment was discontinued because of a lack of efficacy in 2 patients and the development of leukopenia in 1 patient.

\section{MRI analysis}

We obtained brain MRI data for DTI from 9 of the 11 patients. Significant T2-hyperintensities in the brain were absent in all the patients. We subsequently compared the FA values in the white matter between these 9 patients and $24 \mathrm{HCs}$ (table 2) and revealed the presence of significantly decreased FA values, extensively throughout the white matter, including the pyramidal tract and corpus callosum (figure 1A), as well as the absence of significantly increased FA values in the patients as compared to the controls (figure 1B).

\section{Flow cytometric analysis}

We compared the frequencies of B-cell populations, including plasmablasts, memory B cells, and naive B cells, within the $\mathrm{CD} 19^{+}$peripheral blood B cells between the 11 patients and 17 HCs (table 3). The frequency of plasmablasts in the patients was higher than that in HCs $(p=0.0051)$ (figure $2 \mathrm{~B})$, and the frequency of memory B cells in the patients was also higher than that in HCs $(p=0.0456)$ (figure 2C). By contrast, the frequency of naive $\mathrm{B}$ cells in the patients was lower than that in HCs $(p=0.0064)$ (figure 2D).

We had previously reported a similar increase in plasmablasts in patients with NMOSD. ${ }^{13}$ The efficacy of PP in NMOSD is also generally accepted. ${ }^{15}$ Although the presented cases were not diagnosed as having NMOSD, these similarities with NMOSD indicated an autoantibody-mediated pathogenesis, prompting us to use the term "NINJA" to describe the condition in the current cases.

\section{Representative case}

A 38-year-old man had blurred vision in his left eye, which persisted for a week and subsequently dissolved. Two months later, he had painful numbness on the left side of the body. After treatment with IVMP, the sensory disturbance had disappeared almost completely. Six months later, he developed acute left-sided dysesthesia and muscle weakness. Neurologic examination showed left visual impairment, left dominant spastic limb paresis with exaggerated deep tendon

Figure 1 Regional changes in FA values
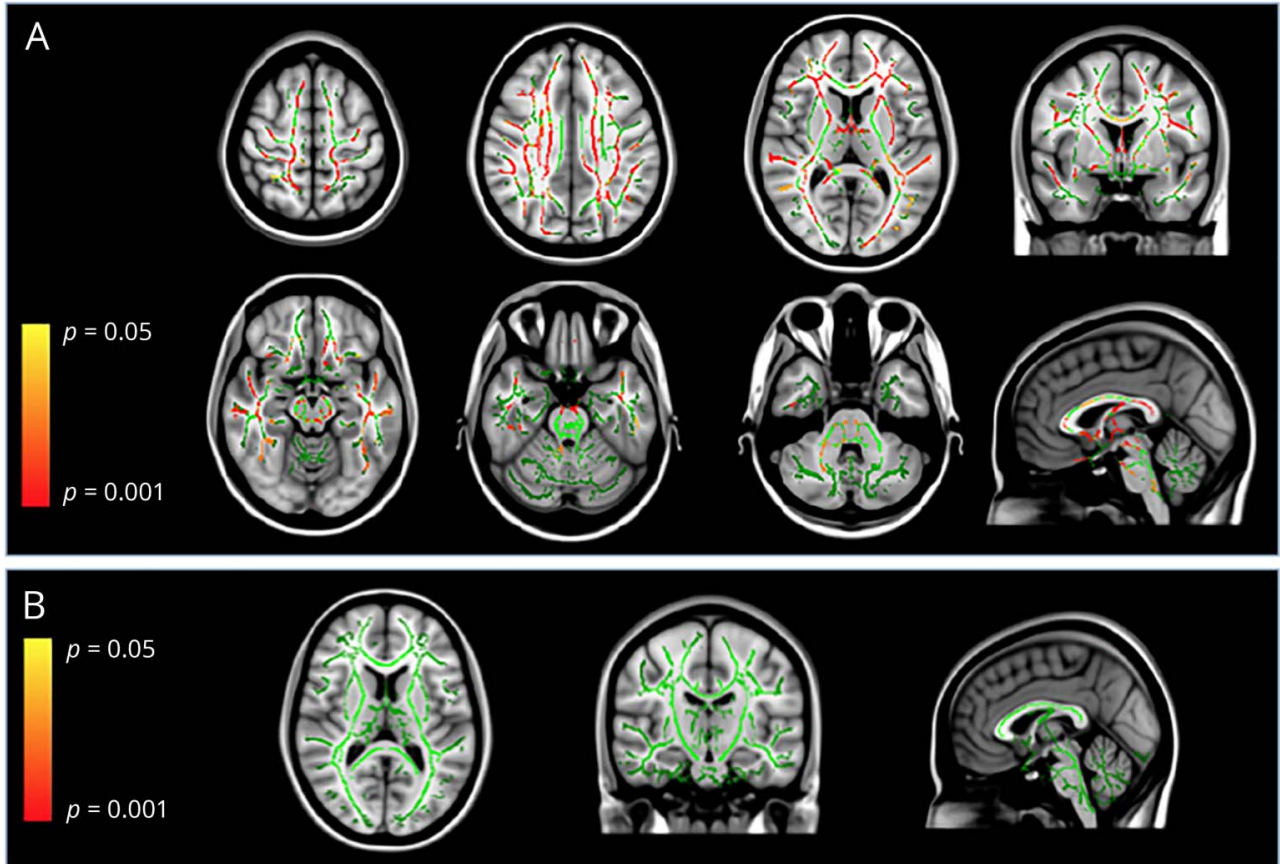

(A) Fractional anisotropy (FA) values were significantly decreased diffusely throughout the white matter, including the pyramidal tract and corpus callosum, in the patients with Normal-appearing Imaging-associated, Neuroimmunologically Justified, Autoimmune encephalomyelitis (NINJA) as compared to controls. (B) Areas with significantly increased FA values were absent in the patients with NINJA as compared to controls. The background image is the standard MNI152 brain template. Green voxels represent the FA of the white matter skeleton. The voxels in which the FA values that are significantly decreased (A) or increased (B) are shown in red or yellow. $p<0.05$ (family-wise error). 
Table 3 Demographics of healthy controls and patients with NINJA in flow cytometric analysis

\begin{tabular}{llll}
\hline & HCs & Patients with NINJA & p Value \\
\hline Number & 17 & 11 & \\
\hline Age (y) & $39.0 \pm 7.9$ & $41.1 \pm 8.0$ & 0.26 \\
\hline Female:male & $14: 3$ & $9: 2$ & 1.00 \\
\hline
\end{tabular}

Abbreviations: $\mathrm{HC}$ = healthy control; NINJA = Normal-appearing Imaging-associated, Neuroimmunologically Justified, Autoimmune encephalomyelitis. Values are expressed as number or mean \pm SD.

reflex and the extensor toe sign on the left side, and sensory disturbance on the left side. Brain and spinal cord MRIs did not reveal any abnormalities. He was suspected of having an autoimmune-mediated neurologic disorder and was treated with IVMP, which was followed by partial recovery of the sensory disturbance in his left arm. Subsequently, we further conducted PP and noticed significant recovery in his gait speed, pyramidal weakness (left arm elevation angle from $-10^{\circ}$ to $+40^{\circ}$ ), and sensory disturbance on the left side. After discharge, however, clinical relapses occurred 3 times a year and disabilities had worsened continuously over the 2 years (deterioration from EDSS score 2.0 to 5.0) (figure e-1A, links.lww.com/NXI/A43), although oral corticosteroids, immunosuppressive drugs (methotrexate, azathioprine, and bucillamine), and glatiramer acetate were given continuously. Repeated MRIs did not reveal any lesions consistent with MS plaques or signs of cerebrovascular accidents.

Figure 2 Frequencies of B-cell subpopulations
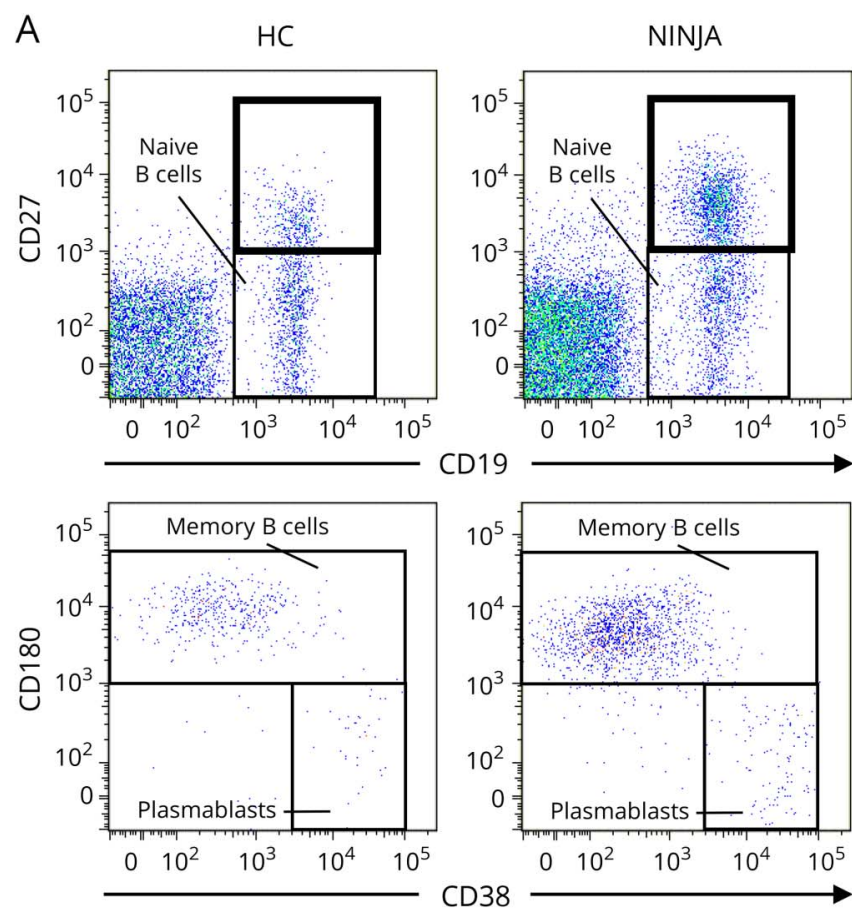

B. Plasmablasts

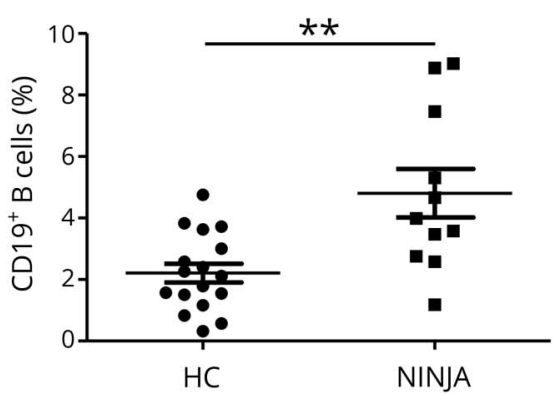

C. Memory B cells

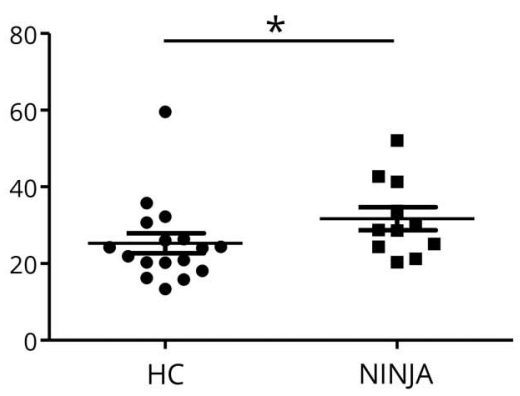

D. Naive B cells

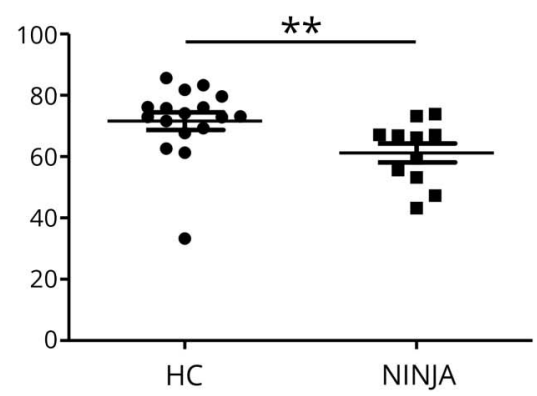

(A) A flow cytometric scheme for the analysis of B-cell subpopulations. Peripheral blood mononuclear cells (PBMCs) from healthy controls (HCs) and patients with Normal-appearing Imaging-associated, Neuroimmunologically Justified, Autoimmune encephalomyelitis (NINJA) were stained with fluorescence-conjugated anti-CD3, CD14, CD19, CD27, CD38, and CD180 monoclonal antibodies. CD3 ${ }^{-}$CD14 $4^{-}$CD19 $9^{+}$CD2 $7^{+}$cells were partitioned (upper) and analyzed for expression of CD38 and CD180 (lower). (B) The frequencies of plasmablasts within CD19 ${ }^{+}$B cells. (C) The frequencies of memory B cells within CD19 $\mathrm{B}$ cells. (D) The frequencies of naive B cells within $\mathrm{CD} 19^{+} \mathrm{B}$ cells $\left({ }^{*} p<0.05,{ }^{\star \star} p<0.01\right.$; Mann-Whitney $U$ test). 


\section{Discussion}

We have here described the clinical, advanced MRI and immunologic characteristics of 11 patients, who had clinical manifestations mimicking MS, but who did not show abnormalities on conventional brain and spinal cord MRIs. Notably, the clinical findings in these 11 cases, including pyramidal weakness and visual impairment with an afferent pupillary defect, suggest covert lesions in the CNS, although they were not detected on conventional brain and spinal cord MRIs. Neurologic disability that accumulated following clinical relapses, as well as abnormalities on SSEP and VEP, is also reminiscent of MS or NMOSD. Nevertheless, the large discrepancy between the clinical symptoms and conventional MRI findings, which appeared normal, would lead experts to hesitate to make a diagnosis of MS, NMOSD, or related disorders and raises concerns about psychiatric or somatoform disorders.

Advanced MRI analysis confirmed a significant decrease in FA values, ${ }^{16}$ which reflect the degree of alignment of cellular structures and their structural integrity, ${ }^{17,18}$ throughout the white matter including the pyramidal tract and corpus callosum, in these patients, as compared to HCs. We also showed that plasmablasts, which are regarded as migratory autoantibody-producing cells, ${ }^{19}$ are significantly increased in the peripheral blood of the patients, reminiscent of the results obtained in patients with NMOSD. NMOSD is characterized by the absence of $\mathrm{OB}^{20,21}$ and an increase in plasmablasts producing anti-AQP4 autoantibody. ${ }^{13}$ Despite testing negative for a range of autoantibodies, the efficacy of PP and IVMP suggests that this condition is mediated by a neuroimmunologic mechanism, possibly involving autoantibodies other than those tested here. A comprehensive overview of these cases indicates that these individuals are having autoimmune-mediated multifocal encephalomyelitis, despite their normal-appearing conventional MRIs. Hence, we propose the provisional term "Normal-appearing Imagingassociated, Neuroimmunologically Justified, Autoimmune encephalomyelitis" or NINJA to describe this potentially treatable condition.

Although the neuropathology of NINJA remains to be studied in additional cases, an extensive reduction in FA values has also been seen in the normal-appearing white matter of patients with $\mathrm{MS} .^{22}$ Of interest, a previous study showed that the degree of decrease in FA values in the normal-appearing white matter in patients with MS correlated with activated microglia rather than with altered axonal or myelin integrity. ${ }^{23}$ One recent report showed that activation of microglia by type I interferon could cause loss of synapses in lupus-prone mice. ${ }^{24}$ This mechanism might provide a hypothetical explanation for the dissociation between clinical manifestations and MRI findings in patients with NINJA. Another report evaluated the cellular and molecular mechanisms underlying the decreased FA values in normal-appearing white matter lesions in older adults and proposed that decreased FA was related to free radical injury to the axonal and myelin elements and the subsequent responses of oligodendrocyte lineage cells to the injury. ${ }^{25}$

In this study, we focused our flow cytometric analysis on B-cell populations because the clinical manifestation of NINJA resembled that of NMOSD rather than that of MS in terms of the unique pattern of opticospinal lesion distribution, absence of $\mathrm{OB},{ }^{20,21}$ and accumulation of disability after clinical relapses. ${ }^{26}$ Plasmablasts have previously been reported to be capable of producing anti-AQP4 antibodies and to be increased in the peripheral blood of patients with NMOSD, but not in patients with conventional Western-type MS, and to show some correlations with disease activity. ${ }^{13}$ Given these reports, we assumed that the increased frequency of plasmablasts within the peripheral blood B cells might account for the autoantibody-mediated pathology in NINJA. A single female patient in our cohort was weakly positive for anti-Ma2 antibody. However, the clinical manifestation of this patient was markedly different from that of previously reported antiMa2-positive patients, ${ }^{27}$ but was consistent with that of other patients with NINJA. Therefore, we assumed that the result was coincidental and not significant.

IFN- $\beta$ is one of the best-known disease-modifying drugs for MS, but this treatment exacerbates the clinical condition of patients with NMOSD. ${ }^{28}$ Testing for anti-AQP4 and antiMOG antibodies, ${ }^{29-34}$ as well as an awareness of the existence of seronegative NMOSD, is very useful for diagnosing NMOSD, for which IFN- $\beta$ should be avoided. ${ }^{35}$ However, even after exclusion of NMOSD, patients with MS who were diagnosed in line with the $2010 \mathrm{McDonald}$ criteria also include those with the category of "non-MS, idiopathic inflammatory diseases." ${ }^{\text {}} 3$ We postulate that NINJA could represent a clinical subgroup in this category.

There were some limitations in this study. As our patient cohort was small and derived from a single facility, the results should be confirmed in prospective, larger-scale, multicenter studies. In addition, we cannot exclude the possibility that the identified 11 patients developed different autoimmune disorders that happened to fulfill the McDonald criteria and that responded to immunotherapy because we lacked an adequate supply of conserved serum or CSF samples before immunotherapy for antibody measurements, and the specificity of the McDonald criteria is limited, particularly for early diagnosis. Therefore, neurologists should be mindful of the possibility of other diseases in their clinical practice. Moreover, because we could not test for well-known neuronal cell surface antibodies in the current sample, these cases might have had disorders associated with these autoantibodies. However, given that the 11 patients in our cohort were suspected of having MS, which has clinical manifestations distinct from the symptoms associated with well-known neuronal cell surface antibodies, we consider this possibility quite low. Finally, we did not have the opportunity to evaluate treatment-naive NINJA patients, so we could not eliminate the effect of immunomodulating drugs 
on the results of lymphocyte subpopulation assays. However, as the immunomodulatory treatments prescribed to the patients are believed to reduce the difference between patients with NINJA and HCs, our results would not be affected by the inclusion of treatment-naive patients.

We have here proposed a distinct disease entity in patients who have a clinical course, signs, and symptoms that mimic MS, but who lack the abnormalities on conventional brain and spinal cord MRIs. This condition, which we have termed "NINJA", is hidden among the psychiatric or somatoform disorders population and is clearly distinct from MS.

\section{Author contributions}

Study design and conceptualization: D. Takewaki, Y. Lin, T. Okamoto, and T. Yamamura. Clinical analysis: D. Takewaki, Y. Lin, W. Sato, M. Araki, T. Okamoto, Y. Takahashi, and T. Yamamura. Flow cytometric analysis: D. Takewaki, W. Sato, H. Ono, M. Nakamura, and T. Yamamura. MRI analysis: Y. Kimura, M. Ota, and N. Sato. Drafting or revising the manuscript for intellectual content: D. Takewaki, W. Sato, and T. Yamamura. Supervising the entire study: T. Yamamura. All authors read and approved submission of the final version of the manuscript.

\section{Acknowledgment}

The authors appreciate the research support from the Japan Multiple Sclerosis Society. The authors thank Dr. Toshiyuki Takahashi at the Department of Neurology, Tohoku University, for examining serum anti-AQP4 antibodies and anti-MOG antibodies in our patients.

\section{Study funding}

This study was supported by the Health and Labour Sciences Research Grants for Comprehensive Research on Persons with Disabilities from the Japan Agency for Medical Research and Development, AMED of Japan (16ek0109084h0002), by Intramural Research Grant (28-5) for Neurological and Psychiatric Disorders of National Center of Neurology and Psychiatry, and by a Health, Labor, and Welfare Sciences Research Grant, for Research on Rare and Intractable Diseases of Japan (H26-nanchito(nan)-ippan-074).

\section{Disclosure}

D. Takewaki reports no disclosures. Y. Lin received speaker honoraria from Asahi Kuraray Medical, Ltd. W. Sato, H. Ono, and M. Nakamura report no disclosures. M. Araki received honoraria from Novartis. T. Okamoto received funding for a clinical trial from Takeda Pharmaceutical Co, Ltd. Y. Takahashi, Y. Kimura, M. Ota, and N. Sato report no disclosures; T. Yamamura served on the scientific advisory board of Biogen Japan, Chugai Pharmaceutical Co, Ltd, and Takeda Pharmaceutical Co; received travel funding and/or speaker honoraria from Novartis Pharma, Nihon Pharmaceutical Co, Ltd, Santen Pharmaceutical Co, Ltd, Abbott Japan Co, Ltd./Eisai Co, Ltd, Biogen Japan, Dainippon Sumitomo Pharma Co, Ltd. Bayer Holding Ltd, Astellas
Pharma Inc, and Takeda Pharmaceutical Co; is an editor of Clinical and Experimental Neuroimmunology; received research support from Ono Pharmaceutical Co, Ltd, Chugai Pharmaceutical Co, Ltd, Teva Pharmaceutical K.K. Mitsubishi Tanabe Pharma Corporation, Asahi Kasei Kuraray Medical Co, Ltd, and the Ministry of Health, Labour and Welfare of Japan. Full disclosure form information provided by the authors is available with the full text of this article at Neurology.org/NN.

Received September 7, 2017. Accepted in final form February 27, 2018.

\section{References}

1. Healy BC, Buckle GJ, Ali EN, et al. Characterizing clinical and MRI dissociation in patients with multiple sclerosis. J Neuroimaging 2017;27:481-485.

2. Polman $\mathrm{CH}$, Reingold SC, Banwell B, et al. Diagnostic criteria for multiple sclerosis: 2010 revisions to the McDonald criteria. Ann Neurol 2011;69:292-302.

3. Jurynczyk M, Geraldes R, Probert F, et al. Distinct brain imaging characteristics of autoantibody-mediated CNS conditions and multiple sclerosis. Brain 2017;140: 617-627.

4. Takahashi T, Fujihara K, Nakashima I, et al. Establishment of a new sensitive assay for anti-human aquaporin-4 antibody in neuromyelitis optica. Tohoku J Exp Med 2006 210:307-313.

5. Kurtzke JF. Rating neurologic impairment in multiple sclerosis: an expanded disability status scale (EDSS). Neurology 1983;33:1444-1452.

6. Sormani MP, De Stefano N. Defining and scoring response to IFN $-\beta$ in multiple sclerosis. Nat Rev Neurol 2013;9:504-512.

7. Ota M, Ishikawa M, Sato N, et al. Pseudo-continuous arterial spin labeling MRI study of schizophrenic patients. Schizophr Res 2014;154:113-118.

8. Ota M, Sato N, Okamoto T, et al. Neuromyelitis optica spectrum disorder and multiple sclerosis: differentiation by a multimodal approach. Mult Scler Relat Disord 2015;4:515-520.

9. Smith SM, Jenkinson M, Johansen-Berg H, et al. Tract-based spatial statistics: voxelwise analysis of multi-subject diffusion data. Neuroimage 2006;31:1487-1505.

10. Smith SM, Jenkinson M, Woolrich MW, et al. Advances in functional and structural MR image analysis and implementation as FSL. Neuroimage 2004;23(suppl 1) S208-S219.

11. Nichols TE, Holmes AP. Nonparametric permutation tests for functional neuroimaging: a primer with examples. Hum Brain Mapp 2002;15:1-25.

12. Smith SM, Nichols TE. Threshold-free cluster enhancement: addressing problems of smoothing, threshold dependence and localisation in cluster inference. Neuroimage 2009;44:83-98.

13. Chihara N, Aranami $\mathrm{T}$, Sato $\mathrm{W}$, et al. Interleukin 6 signaling promotes anti-aquaporin 4 autoantibody production from plasmablasts in neuromyelitis optica. Proc Natl Acad Sci U S A 2011;108:3701-3706.

14. Nakamura M, Matsuoka $\mathrm{T}$, Chihara N, et al. Differential effects of fingolimod on B-cell populations in multiple sclerosis. Mult Scler 2014;20:1371-1380.

15. Keegan M, Pineda AA, McClelland RL, Darby CH, Rodriguez M, Weinshenker BG. Plasma exchange for severe attacks of CNS demyelination: predictors of response. Neurology 2002;58:143-146.

16. Pawlitzki M, Neumann J, Kaufmann J, et al. Loss of corticospinal tract integrity in early MS disease stages. Neurol Neuroimmunol Neuroinflamm 2017;4:e399.

17. Basser PJ, Mattiello J, LeBihan D. Estimation of the effective self-diffusion tensor from the NMR spin echo. J Magn Reson B 1994;103:247-254.

18. Basser PJ, Pierpaoli C. Microstructural features measured using diffusion tensor imaging. J Magn Reson B 1996;111:209-219.

19. Chihara N, Aranami T, Oki S, et al. Plasmablasts as migratory IgG-producing cells in the pathogenesis of neuromyelitis optica. PLoS One 2013;8:e83036.

20. Bergamaschi R, Tonietti S, Franciotta D, et al. Oligoclonal bands in Devic's neuromyelitis optica and multiple sclerosis: differences in repeated cerebrospinal fluid examinations. Mult Scler 2004;10:2-4.

21. Jarius S, Paul F, Franciotta D, et al. Cerebrospinal fluid findings in aquaporin-4 antibody positive neuromyelitis optica: results from 211 lumbar punctures. J Neurol Sci 2011;306:82-90.

22. Vrenken H, Pouwels PJ, Geurts JJ, et al. Altered diffusion tensor in multiple sclerosis normal-appearing brain tissue: cortical diffusion changes seem related to clinical deterioration. J Magn Reson Imaging 2006;23:628-636.

23. Moll NM, Rietsch AM, Thomas S, et al. Multiple sclerosis normal-appearing white matter: pathology-imaging correlations. Ann Neurol 2011;70:764-773.

24. Bialas AR, Presumey J, Das A, et al. Microglia-dependent synapse loss in type I interferon-mediated lupus. Nature 2017;546:539-543.

25. Back SA, Kroenke CD, Sherman LS, et al. White matter lesions defined by diffusion tensor imaging in older adults. Ann Neurol 2011;70:465-476.

26. Wingerchuk DM, Hogancamp WF, O'Brien PC, Weinshenker BG. The clinical course of neuromyelitis optica (Devic's syndrome). Neurology 1999;53:1107-1114.

27. Voltz R, Gultekin SH, Rosenfeld MR, et al. A serologic marker of paraneoplastic limbic and brain-stem encephalitis in patients with testicular cancer. N Engl J Med 1999;340:1788-1795. 
28. Shimizu J, Hatanaka $Y$, Hasegawa $M$, et al. IFN- $\beta$ - $1 \mathrm{~b}$ may severely exacerbate Japanese optic-spinal MS in neuromyelitis optica spectrum. Neurology 2010;75:1423-1427.

29. Lennon VA, Wingerchuk DM, Kryzer TJ, et al. A serum autoantibody marker of neuromyelitis optica: distinction from multiple sclerosis. Lancet 2004;364:2106-2112.

30. Lennon VA, Kryzer TJ, Pittock SJ, Verkman AS, Hinson SR. IgG marker of optic-spinal multiple sclerosis binds to the aquaporin-4 water channel. J Exp Med 2005;202:473-477.

31. Wingerchuk DM, Lennon VA, Lucchinetti CF, Pittock SJ, Weinshenker BG. The spectrum of neuromyelitis optica. Lancet Neurol 2007;6:805-815.

32. Kitley J, Woodhall M, Waters $\mathrm{P}$, et al. Myelin-oligodendrocyte glycoprotein antibodies in adults with a neuromyelitis optica phenotype. Neurology 2012;79:1273-1277.
33. Mader S, Gredler V, Schanda K, et al. Complement activating antibodies to myelin oligodendrocyte glycoprotein in neuromyelitis optica and related disorders. J Neuroinflammation 2011;8:184.

34. Sato DK, Callegaro D, Lana-Peixoto MA, et al. Distinction between MOG antibodypositive and AQP4 antibody-positive NMO spectrum disorders. Neurology 2014;82 474-481.

35. Wingerchuk DM, Banwell B, Bennett JL, et al. International consensus diagnostic criteria for neuromyelitis optica spectrum disorders. Neurology 2015;85:177-189.

36. Miller DH, Weinshenker BG, Filippi M, et al. Differential diagnosis of suspected multiple sclerosis: a consensus approach. Mult Scler 2008;14:1157-1174. 


\title{
Neurology \\ Neuroimmunology \& Neuroinflammation
}

\author{
Normal brain imaging accompanies neuroimmunologically justified, autoimmune \\ encephalomyelitis \\ Daiki Takewaki, Youwei Lin, Wakiro Sato, et al. \\ Neurol Neuroimmunol Neuroinflamm 2018;5; \\ DOI 10.1212/NXI.0000000000000456
}

This information is current as of April 2, 2018

\section{Updated Information \& \\ Services}

References

Subspecialty Collections

Permissions \& Licensing

Reprints including high resolution figures, can be found at:

http://nn.neurology.org/content/5/3/e456.full.html

This article cites 36 articles, 2 of which you can access for free at: http://nn.neurology.org/content/5/3/e456.full.html\#\#ref-list-1

This article, along with others on similar topics, appears in the following collection(s):

MRI

http://nn.neurology.org//cgi/collection/mri

Multiple sclerosis

http://nn.neurology.org//cgi/collection/multiple_sclerosis

Information about reproducing this article in parts (figures,tables) or in its entirety can be found online at:

http://nn.neurology.org/misc/about.xhtml\#permissions

Information about ordering reprints can be found online: http://nn.neurology.org/misc/addir.xhtml\#reprintsus

Neurol Neuroimmunol Neuroinflamm is an official journal of the American Academy of Neurology.

Published since April 2014, it is an open-access, online-only, continuous publication journal. Copyright

Copyright (C) 2018 The Author(s). Published by Wolters Kluwer Health, Inc. on behalf of the American

Academy of Neurology.. All rights reserved. Online ISSN: 2332-7812.

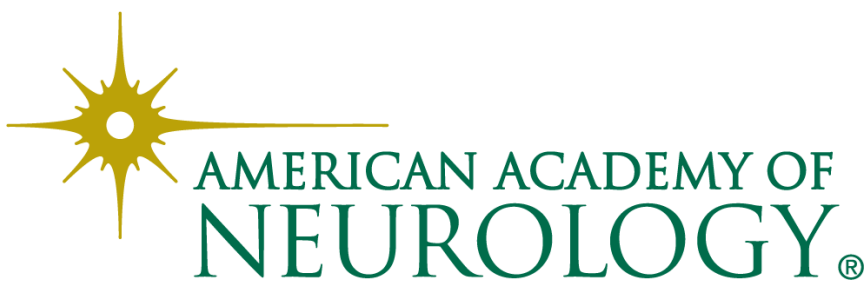

